\title{
Early detection of IUGR: can it prevent stillbirth?
}

\author{
Ashwini Vishalakshi L.*, Reddi Rani P. \\ Department of Obstetrics and Gynecology, Mahatma Gandhi Medical College and Research Institute, Sri Balaji \\ Vidyapeeth University (SBV), Pilliyarkuppam, Pondicherry, India
}

Received: 18 June 2018

Accepted: 24 July 2018

\section{*Correspondence:}

Dr. Ashwini Vishalakshi L.,

E-mail: akshivishal@gmail.com

Copyright: ( ) the author(s), publisher and licensee Medip Academy. This is an open-access article distributed under the terms of the Creative Commons Attribution Non-Commercial License, which permits unrestricted non-commercial use, distribution, and reproduction in any medium, provided the original work is properly cited.

\begin{abstract}
Background: Maternal mortality in India is decreasing with the advances in health care facilities, increase in the number of hospital deliveries, improvement in the transport facilities etc. Present study aimed at to evaluate the causes for antepartum stillbirths.

Methods: It is a retrospective study from the case records of the stillbirths that occurred from June 2015 to March 2018. All stillbirths between $28-41$ weeks were studies. Stillbirths occurring in twin pregnancies were excluded. The total number of stillbirths that were studied was 102.

Results: Most of the IUDs occurred between 28-37 weeks 82 (80.39\%). The mean period of gestation at which the stillbirth occurred was $33.84 \pm 3.8$ weeks. There was more number of male stillborns as compared to female stillborns. When the weight distribution of all stillbirths was compared with weight for gestational age $48(47.5 \%)$ were $<10 \%$ (SGA) and $46(45.09 \%)$ of stillbirths weighed between $10^{\text {th }}$ and $50^{\text {th }}$ percentile Most of the IUDs were caused due to cord accidents, abruption and as a complication of hypertensive disorders of pregnancy.

Conclusions: Stillbirths were higher in IUGR fetusus as compared to AGA fetuses. Hence in order to prevent stillbirth it would be mandatory to detect IUGR at an earlier stage and delivery should be planned if the fetus shows any features of compromise. Doppler studies can help in deciding the timing of delivery.
\end{abstract}

Keywords: Stillbirth, IUGR, Small for gestational age (SGA)

\section{INTRODUCTION}

Maternal mortality in India is decreasing with the advances in health care facilities, increase in the number of hospital deliveries, improvement in the transport facilities ect. But unlike the drastic decrease in maternal mortality perinatal mortality has decreased only slightly. Stillbirth can be because of intrapartum causes or antepartum causes. Half of all stillbirths happen during the intrapartum period in the developing countries. Whereas in developed countries antepatum fetal deaths are the major contributors of perinatal mortality. A study of the contributing causes for stillbirth could reduce the incidence if preventable cause for stillbirth is present, because fetal deaths due to unexplained causes are difficult to avoid.

Classification systems for classifying stillbirths are many like Aberdeen, modified Wigglesworth and ReCoDe classification. ReCoDe is currently the only classification system specifically developed for classification of causes of stillbirth. It is clinically based. So it is appropriate for developing countries where only minimal investigations are possible. It also identifies $85 \%$ of causes for stillbirth unlike the other classifications which identify only one third causes of stillbirth leaving most unclassified/unexplained. ${ }^{1}$ 
Various studies have found that the most common cause for antepartum deaths were unexplained deaths, deaths due to hypertensive disorders and antepartum hemorrhage. $^{2}$ Increased risk of stillbirth was seen in women of African American race, advanced maternal age, obesity, multiple pregnancies, maternal medical disorders (SLE, diabetes, hypertension, thrombophilias, infection, history of infertility). ${ }^{3}$ The biological markers that suggest an increased risk of stillbirth are hemoconcentration and decreased PAPP-A in first trimester screening. Smith et al found that women with decreased PAPP-A levels in the first trimester were at increased risk for adverse fetal outcome in the second trimester like preterm birth, preeclampsia and stillbirth. ${ }^{4}$

IUGR was seen more commonly in preterm deliveries as compared to term deliveries. ${ }^{5-7}$ According to a study done by Bukowski et al $10 \%$ of fetus in preterm deliveries were IUGR as compared to only $2 \%$ in term deliveries. ${ }^{8}$ Preterm delivery may be the nature's way of saving the IUGR fetuses from antepartum deaths. Similarly antepartum deaths can be prevented by early detection of IUGR and delivery at the earliest in case of fetal compromise.

Since most of the stillbirths occur preterm, weight for gestational age is taken for assessing risk. Williams et al analyzed 23,000 stillbirths and demonstrated a strong link between decreased fetal-weight-for-gestation and fetal demise. ${ }^{9}$ Analysis of Swedish birth register also demonstrated a strong association of small for gestation fetus and increased risk of stillbirth. Our study is done to assess the various causes for stillbirth in our population so as to avoid antepartum stillbirths.

\section{METHODS}

This is a retrospective study done in the Department of Obstetrics and Gynecology, Mahatma Gandhi Medical Hospital and Research Institute, Pondicherry, India. The stillbirths that occurred in our hospital during the period June 2015 to March 2018 were taken for the study. There was only 1 intrapartum stillbirth. Remaining were antepartum deaths.

Inclusion criteria were singleton intrauterine fetal deaths diagnosed antepartum after 28 weeks of gestation calculated from the last menstrual period and confirmed by first trimester ultrasound. Stillbirths occurring in twin pregnancies were excluded. Deaths due to intrapartum complications were also excluded. Cases were also excluded when the period of gestation could not be estimated with accuracy (unreliable last menstrual period and not confirmed by first trimester scan).

Antenatal women with at least 4 antenatal visits were considered as booked cases and those less than 4 were considered unbooked. All stillbirths above 28 weeks were studies. Maternal demographic details like age, parity, number of previous abortions, intrauterine deaths were noted. Associated preexisting medical disorders (diabetes, hypertension, cardiac diseases, SLE, thrombophilia, rh negative pregnancy) and obstetric complications (GDM, preeclampsia, abruption, PROM, PPROM, cord prolapse) were recorded. Hypertension in pregnancy was classified according to recommendation by the International Society for Study of Hypertension in Pregnancy. Other parameters studied were gender of the fetus, fetal weight, and gestational age at diagnosis of stillbirth. Gestation age of the fetus was calculated by subtracting 3 days from the day of diagnosis of intrauterine death.

Placental abnormalities, cord abnormalities, presence of retroplacental clots and congenital anomalies in the fetus were noted. The cause for stillbirth was classified as per ReCoDe classification 1 . When no cause of stillbirth was found it was classified as unexplained. Three gestational periods were defined 28-32 weeks, 33-37 weeks and $>37$ weeks.

Fetal growth percentile was calculated by calculating fetal weight for gestational age and comparing it with the standard values as per Alexander's smoothed percentiles of birth weight for gestational age. ${ }^{10}$ Fetuses weighing less than $10^{\text {th }}$ percentile were considered SGA, weight more than $90^{\text {th }}$ percentile was classified as LGA.

Categorical variables were noted in numbers and percentages. Continuous data was expressed as mean with standard deviation.

\section{RESULTS}

The total number of stillbirths that matched with the inclusion criteria were 102. The total number of deliveries in this period was 4275 . The stillbirth rate was $26.19 \%$. Out of the total 102 cases 98 were booked and 4 were unbooked. The mean maternal age was $26.43 \pm 4.18$ years.

Table 1: Antenatal profile of women.

\begin{tabular}{|lll|}
\hline \multicolumn{2}{|l|}{ Number } & Percentage \\
\hline Bntenatal check up & & \\
\hline Booked & 98 & 96.07 \\
\hline Unbooked & 4 & 3.9 \\
\hline Gestational age & & \\
\hline 28-32 weeks & 44 & 43.1 \\
\hline 33-37 weeks & 38 & 37.2 \\
\hline >37 weeks & 20 & 19.6 \\
\hline Parity & & \\
\hline Primigravida & 53 & 51.96 \\
\hline Multigravida & 49 & 48.03 \\
\hline Previous h/o IUD & 7 & 6.86 \\
\hline Previous h/o abortion & 23 & 22.54 \\
\hline
\end{tabular}

Table 1 shows the antenatal profile of all women included in the study. There were 53 (51.96\%) 
primigravidas and $49(48.03 \%)$ multigravidas. Most of the IUDs occurred preterm between 28-37 weeks 82 $(80.39 \%)$ whereas IUDs after 37 weeks were only 20 (19.6\%). There were 44(43.1\%) stillbirths between $28-32$ weeks and $38(37.2 \%)$ stillbirths between 33-37 weeks. The mean period of gestation at which the stillbirth occurred was $33.84 \pm 3.8$ weeks. A history of previous IUD was seen in 7 women $(6.86 \%)$ and $23(22.54 \%)$ had a history of at least one abortion. Male fetus seemed to be at a higher risk for intrauterine death. There were 57 (55.88\%) male stillborns as compared to 45 (44.11\%) female stillborns. The mean birth weight was $1736 \pm 778.98$ gms.

Table 2: Causes of stillbirth.

\begin{tabular}{|lll|}
\hline & Number & Percentage \\
\hline Unexplained & 30 & 29.4 \\
\hline Hypertensive disorders & 25 & 24.5 \\
\hline Abruption & 17 & 16.66 \\
\hline Anomalies & 12 & 11.76 \\
\hline Diabetes & 5 & 4.9 \\
\hline Cord accidents & 13 & 12.7 \\
\hline & 102 & 100 \\
\hline
\end{tabular}

Table 2 shows the distribution of the probable cause for IUDs. Most of the IUDs were caused due to cord accidents, abruption and as a complication of hypertensive disorders of pregnancy. Cord accidents include presence of true knot (2 cases) and tight cord around the neck (11 cases). In $29.4 \%$ of the cases the cause for IUD was unexplained.

A skewed distribution was seen in the birth weight of the stillborn fetuses since most were preterm deliveries. Most $86(84 \%)$ were $<2500$ gms (low birthweight fetuses). Among them VLBW were $44(43.13 \%)$. Only 16 $(15.68 \%)$ of the stillbirth weighed more than $2.5 \mathrm{~kg}$. When the weight distribution of all stillbirths was compared with weight for gestational age $48(47.5 \%)$ were $<10 \%$ (SGA) and $46(45.09 \%)$ of stillbirths weighed between 10th and 50th percentile. Only $8(7.04 \%)$ of stillbirth fetuses weighed $>50^{\text {th }}$ centile.

\section{DISCUSSION}

Various factors are known to cause IUD. From the analysis of our study most of the stillbirths can be prevented. We see that most of the stillborns belong to the SGA group. Despite various studies suggesting that palpation and symphysio-fundal height measurement are ineffective in detecting growth restriction most of the patients have only clinical examination done to assess fetal growth. ${ }^{11}$ The application of USG to monitor the fetal growth in addition to routine clinical assessment may help in preventing stillbirth as ultrasound can detect growth restriction of the fetus at an earlier stage as compared to clinical examination. Also, Doppler measurement helps us to detect and differentiate pathological IUGR from constitutionally small fetuses. ${ }^{12,13}$ It also helps us in planning the optimum timing for delivery.

Of all the stillbirths in our study $11.76 \%$ are due to gross fetal anomalies. Routine detailed ultrasound by an experienced radiologist between 18-20 weeks should be advised to detect the gross and lethal fetal anomalies so as to terminate the pregnancy at the earliest in case of lethal fetal anomalies.

In a study by Lavin et al a large proportion of stillbirths occurred during 33-37 weeks in SGA fetuses. ${ }^{14}$ Whereas, in AGA and LGA fetuses stillbirth rates were same across the gestational ages. In present study 44 (43.1\%) stillbirths were between 28-33weeks of gestation and 38 (37.2\%) were between 33-38 weeks. Only 20 (19.6\%) stillbirths were term stillbirths. The cause of death in their study was IUGR (91.3\%), hypertensive disorders (37\%), fetal abnormality $(33.3 \%)$, and spontaneous preterm labor $(36 \%)$.

But in the study by JG Ray et al deaths due to unknown causes was the maximum $(54.3 \%)$ whereas stillbirths due to anomalies was $10.5 \%$, placental disease was $15.6 \%$ and due to infection was $1.2 \% .^{15}$

The results of a study by Lavin et al is similar to our study where the cause of death was IUGR $(92.1 \%)$, hypertensive disorders $(24.5 \%)$, and fetal abnormalities were $(11.76 \%)$. In addition to the above causes in our study there were a significant number of stillbirths that were due to cord accidents such as tight cord around the neck and true knot of the cord (12.7\%). A study by Korteweg et al showed umbilical cord complication rate of $5.2 \%$, which presented mainly as strangulation in term period. ${ }^{16}$

Jason et al showed in their study that fetal growth restriction had the largest population attributable risk for stillbirth and it was fivefold greater when it was not detected antenatally. ${ }^{17}$ Thus suboptimal antenatal care due to various reasons could be the cause for a majority of stillbirths. These stillbirths might have been prevented if IUGR was diagnosed early and measures for optimum timing of delivery were taken. Customized growth charts can be useful in early identification of growth restricted fetus. It also decreases the false alarms in constitutionally small fetuses.

The limitations of our study were that it was a retrospective study. Even though corrected gestational age was taken the estimated time of death might not have been accurate which may have influenced the proportion of AGA, SGA and LGA fetus.

\section{CONCLUSION}

Many stillbirths seem to be preventable if detection of high risk cases was done early. Although the antenatal 
care services have improved more focus should be given on ultrasound estimation of fetal growth as compared to clinical examination alone.

Funding: No funding sources

Conflict of interest: None declared

Ethical approval: The study was approved by the Institutional Ethics Committee

\section{REFERENCES}

1. Gardosi J, Kady SM, McGeown P. Classification of stillbirth by relevant condition at death $(\mathrm{ReCoDe})$ : Population based cohort study. $\mathrm{Br}$ Med J. 2005;3331:1113-7.

2. Jason G, Theo Mul, Max M, David F. Analysis of birthweight and gestational age in antepartum stillbirths. Br J Obstet gynecol 1998;105:524-530

3. Ruth CF. Etiology and prevention of Stillbirth. Am J Obstet Gynecol. 2005;193:1923-35.

4. Smith GC, Stenhouse EJ, Crossley JA, Aitken DA, Cameron AD, Connor JM. Early pregnancy levels of pregnancy associated plasma protein a and the risk of intrauterine growth restriction, premature birth, preeclampsia and stillbirth. J Clin Endocrinol Metab. 2002;87:1762-7.

5. Bernstein IM, Horbar JD, Badger GJ et al. Morbidity and mortality among very-low birth weight neonates with intrauterine growth restriction: the Vermont Oxford Network. Am J Obstet Gynecol. 2000; 182:198-206.

6. Zeitlin JA, Aneel PY, Saurel-Cubezolles MJ, Papiernik E. Are risk factors the same for small for gestational age versus other preterm births?. Am J Obstet Gynecol. 2001;185:208-15.

7. Bukowski R, Gahn D, Denning J, Saade G. Impairment of growth in fetuses destined to deliver preterm. Am J Obstet Gynecol. 2001;185:463-7.

8. Buowski R, Hansen NI, Willinger M, Reddy UM, Parker CB et al. Fetal growth and risk of stillbirth: a population-based-case-control study. PLOS Med. 2014;11(4):e1001633.

9. Williams RL, Creasy RK, Cunningham GC et al. Fetal growth and perinatal viability in California. Obstetrics and Gynecol. 1982;59(5):624-32.

10. Alexander GR et al.: A United States national reference for fetal growth Obstet Gynecol. 1996;87(2):163-8.

11. Peter JR, Ho JJ, Valliappan J, Sivasangari S. Symphysial fundal height measurement in pregnancy for detecting abnormal fetal growth. BJOG-Int J Obstet Gynecol. 2012;119-78.

12. Reuwer PJ, Bruinse HW, Stoutenbeek P, Haspels AA. Doppler assessment of the fetoplacental circulation in normal and growth-retarded fetuses. Eur J Obstet Gyneco Reprod Biol. 1984;18(4):199205.

13. Neilson JP, Alfirevic Z. Doppler ultrasound for fetal assessment in high risk pregnancies. Cochrane Database Sys Rev. 2000;2:CD000073.

14. Lavin T, David B, Preen, Robert P. Timing and cause of perinatal mortality for small-for-gestational age babies in South Africa: critical periods and challenges with detection. Mat Health Neonatol Prinatol. 2016;2:11.

15. Ray JG, Urquia ML. Risk of stillbirth at extremes of birthweight between 20-41 weeks gestation. J Perinatol. 2012;32(11):829-36.

16. Korteweg FJ, Erwich JJ, Holm JP, Ravise JM, Van der Meer J, Veeger NJ et al. Diverse placental pathologies as the main cause of fetal death. Obstet Gynecol. 2009;114;809-17.

17. Jason G, Vichithranie M, Mandy W, Asad M, Andre F. Maternal and fetal risk factors for stillbirth: population based study. BMJ. 2013;346:f108.

Cite this article as: Vishalakshi AL, Rani RP. Early detection of IUGR: can it prevent stillbirth?.Int J Reprod Contracept ObstetGynecol 2018;7:3629-32. 